\title{
Vascular Tissue Engineering: Advanced Techniques and Gene Editing in Stem Cells for Graft Generation
}

\begin{abstract}
Sin-Guang Chen, MSc, PhD, ${ }^{1}$ Felix Ugwu, MSc, PhD, ${ }^{2}$ Wan-Chun Li, MSc, PhD, ${ }^{3}$ Noel M Caplice, MD, PhD, ${ }^{4}$ Eugen Petcu, MD, MSc, PhD, ${ }^{5}$ Shea Ping Yip, MPhil, PhD, ${ }^{6,}{ }^{*}$ and Chien-
\end{abstract} Ling Huang, MSc, $\mathrm{PhD}^{7, *}$

${ }^{1}$ Department of Health Technology and Informatics, The Hong Kong Polytechnic University, Kowloon, Hong Kong SAR, China; E-mail: singuang.chen@polyu.edu.hk; Tel.: $+852-3400-8602$

${ }^{2}$ Department of Health Technology and Informatics, The Hong Kong Polytechnic University, Kowloon, Hong Kong SAR, China; E-mail: felix.ugwu@connect.polyu.hk; Tel.: $+852-3400-8602$

${ }^{3}$ Institute of Oral Biology, School of Dentistry, National Yang-Ming University, Taipei, Taiwan, ROC; E-mail: wcli@ym.edu.tw; Tel.: +886-2-2826-7255

${ }^{4}$ Centre for Research in Vascular Biology, Biosciences Institute, University College Cork, Cork, Ireland; E-mail: n.caplice@ucc.ie; Tel.: +353214901326

${ }^{5}$ Griffith University School of Medicine, Menzies Health Institute Queensland, Griffith University, Australia; E-mail: e.petcu@griffith.edu.au; Tel.: +61 756788811

${ }^{6}$ Department of Health Technology and Informatics, The Hong Kong Polytechnic University, Kowloon, Hong Kong SAR, China; E-mail: shea.ping.yip@polyu.edu.hk; Tel.: $+852-3400-8571$

${ }^{7}$ Department of Health Technology and Informatics, The Hong Kong Polytechnic University, Kowloon, Hong Kong SAR, China; E-mail: cl.huang@polyu.edu.hk; Tel.: +8523400-8602

*Correspondence should be addressed to:

Chien-Ling HUANG, Ph.D.

Tel.: $+852-3400-8602$

E-mail: cl.huang@polyu.edu.hk 
Page 2 of 42

Shea Ping YIP, Ph.D.

Tel.: +852-3400-8571

要

E-mail: shea.ping.yip@polyu.edu.hk 
ABSTRACT

The common occurrence of cardiovascular diseases and the lack of proper autologous tissues prompt and promote the pressing development of tissue-engineered vascular grafts. Current progress on scaffold production, genetically modified cells and use of nanotechnology-based monitoring has considerably improved the long-term patency of engineered tissue grafts. However, challenges abound in the autologous materials and manipulation of genes and cells for tissue engineering. This review overviews current development in tissue-engineered vascular grafts and discusses recent improvements in scaffolding techniques as well as the efficiency of gene-editing tools and their ability to fill the existing gaps in stem-cell and regenerative therapies. Current advances in 3D-printing approaches for fabrication of engineered tissues are also reviewed together with specific biomaterials for vascular tissues. In addition, the natural and synthetic polymers that hold increasing significance for vascular tissue engineering are highlighted. Both animal models and nanotechnology-based monitoring are proposed for pre-clinical evaluation of engineered grafts in view of their historical significance in tissue engineering. The ultimate success of tissue regeneration, which is yet to be fully realized, depends on the optimal performance of culture systems, biomaterial constructs and stem cells in a suitable artificial physiological environment.

Keywords: vascular tissue engineering, tissue-engineered vascular graft, 3D bioprinting, stem cell, CRISPR/Cas9, pre-clinical evaluation 
Impact Statement

The main goal of this review is to provide a broadened insight on recent advances in stem cell-based vascular tissue engineering and the development of gene-editing and nanotechnology systems in this field. Moreover, the uses of autologous cells to prepare personalized hydrogels offer promising methods for scaffold fabrication. These new approaches not only improve the efficacy of tissue-engineered vascular grafts, but also offer potential therapeutic options with long-term beneficial effects on patients. 
Introduction

Cardiovascular diseases (CVDs) are the leading causes of mortality worldwide. ${ }^{1}$ The majority of CVDs is atherosclerosis characterized by the formation in the arterial intima of plaques containing lipid and cells. ${ }^{2}$ When affected blood vessels are narrowed or blocked, the decrease of blood flow induces ischemic tissue damage due to inadequate nutrient supply. According to the World Health Organization, the global mortality rate of CVDs is projected to be 268.6 deaths per 100,000 people per year by $2030 .^{3}$ The abnormal narrowing of blood vessels can be treated with endovascular surgeries such as angioplasty, atherectomy or stent insertion to widen stenosis or remove plaque. ${ }^{4}$ On the other hand, blocked or damaged blood vessels can be replaced or bypassed with a vascular graft. $^{5}$ Although endovascular surgeries are popular treatment options, vascular grafting is the optimal solution for long-term patency in patients. ${ }^{5}$ Currently, autologous arteries or veins such as internal thoracic arteries, radial arteries and saphenous veins are the favored conduits for replacing diseased blood vessels. ${ }^{6}$ However, the use of autologous vessels to reconstruct or bypass vascular occlusions and aneurysms is unsuitable for many patients because of pre-existing vascular disease or vein stripping/harvesting for previous vascular procedures. ${ }^{7}$ Alternatively, vascular grafts with proper patency rates may be used to replace or bypass damaged vascular conduits. ${ }^{5}$

Synthetic vascular grafts for replacing blocked blood vessels have been introduced for clinical use as an alternative to autologous vessels since the 1950 s. $^{1}$ These largediameter synthetic vascular grafts $(>6 \mathrm{~mm}$ ) have been performing well with long-term patency rates. ${ }^{8}$ The five-year patency of aorto-iliac replacement with synthetic vascular grafts is $90 \%$. However, synthetic grafts made of polyethylene terephthalate (Dacron), polytetrafluoroethylene (PTFE) or polyurethane can pose problems especially in small vessels $(<6 \mathrm{~mm}) \cdot{ }^{9,10}$ Similar to small autologous blood vessel transplantation, vascular graft failures are caused by intimal hyperplasia within the vessel wall, thrombosis, lack of re-endothelialization, atherosclerosis, inflammation and infection. ${ }^{5,11}$ Synthetic grafts provide new biomaterials with acellular synthetics for in vivo testing, and their limitations have been reviewed. ${ }^{1,5,12}$ The application of synthetic grafts in small-diameter vessels is still not well developed owing to gradually decreasing patency when compared with 
autologous vascular grafts. ${ }^{13}$ Seeding of autologous vascular endothelial cells (ECs) onto the luminal surface of synthetic grafts can improve the patency, but these grafts do not perform as well as autologous vessels. ${ }^{14,15}$

Given the shortage of available vascular bypass conduits, tissue engineering technology combines cells, tissue scaffold and engineering to generate vascular graft, and is thus a potential solution for vascular surgery. ${ }^{16} \mathrm{~A}$ tissue-engineered vascular graft (TEVG) generated in vitro does not require invasive surgery to harvest vascular tissues from patients. Development of functional TEVGs is essential for other applications of tissue engineering. ${ }^{17}$ One of the major barriers to tissue engineering is the need to supply nutrition and oxygen to tissues through a microvascular system. Tissue blocks thicker than 100-200 $\mu \mathrm{m}$ are difficult to be maintained ex vivo by diffusive transport of nutrients, oxygen and waste products. The establishment of a perfusable vascular system is essential for the graft engineering of tissues or organs. The prevascularization can be achieved by stimulation of angiogenesis via either seeding of endothelial cells or re-endothelialization of decellularized extracellular matrix (ECM). The engineered vessels must tolerate physiological pressures, and should not induce any immunological response or blood clot formation. $^{12,18}$

This review provides a translational outlook of current progress in vascular tissue engineering and the advancements in stem/progenitor cell-mediated vascular tissue regeneration. It discusses the emerging roles of gene-editing and nanotechnology systems in this field, highlights technological developments for clinical applications, and identifies challenges of future research for vascular regenerative therapy.

\section{Novel Scaffolds and Scaffolding Techniques for TEVGs}

Several different approaches have been used to construct TEVGs for clinical use. According to established techniques, TEVGs can be categorized as scaffold-based vascular grafts based on synthetic, natural or hybrid materials, or as self-assembled vascular grafts. $^{19}$

Most normal cells except blood cells are anchorage-dependent, residing in a solid matrix. ${ }^{20}$ Ideal scaffolds for tissue engineering should be non-immunogenic, non-toxic and 

is commonly used in TEVGs (Fig. 1).

Synthetic and natural substrates. Synthetic substrates can be easily manipulated into a variety of structures in a reproducible manner and have controllable mechanical properties. $^{22,23}$ However, no single polymer possesses all essential properties for constructing TEVGs in terms of biocompatibility, biodegradability and mechanical strength. To generate better grafts with improved scaffold construction, copolymers combining with different polymers have been well developed in tissue engineering. ${ }^{24-26}$ Readers interested in this field can find more details in a very recent review. ${ }^{27}$ The scaffolds made by synthetic substrates can serve as the basis of TEVGs for seeding specific cell types; however, several limitations obstruct their applications in vascular engineering, including poor cell adhesion, poor proliferation, frequent thrombosis formation, decreased matrix synthesis, low void volumes and persistent polymer remnants. ${ }^{17,22,23,28}$

Natural biomaterials display excellent biocompatibility for cell attachment and growth, but their limited physical and mechanical stability is a significant obstacle to tissue engineering application. ${ }^{29}$ Several additional modifications including cross-linking and forming composites with synthetic material have been developed to improve and enhance the stability of these natural biomaterials. ${ }^{30-32} \mathrm{ECM}$ is an essential non-cellular component with 3D microenvironment for cell attachment. ${ }^{33}$ Several common components derived from ECM, such as collagen and fibrin, are widely applied in gel format for constructing cell-bearing scaffolds. These hydrogel-based scaffolds have been successfully used for the development of small-diameter vascular grafts. ${ }^{34-36}$ In addition to ECM, decellularized natural matrices derived from animal tissues have also shown their potential in constructing TEVGs (Fig. 2). ${ }^{37}$ However, major failures of decellularization-based vascular grafts are caused by aneurysm, graft-related thrombosis and infection. ${ }^{5,38}$ 
Scaffolds derived from synthetic or natural substrates provide a promising way to establish TEVGs and are applicable as anastomosis grafts used in animal models. However, several disadvantages of scaffold-based TEVGs limit their applications: i) it is unacceptable for patients with urgent need because manufacturing TEVGs takes more than a few months; ii) host immune response against scaffold or allogenic cells contributes to TEVG failure; iii) cellular senescence restrains cellular proliferation in vitro; and iv) improper mechanical property of TEVGs compared with natural blood vessels can cause aneurysm formation. Recent advances in 3D printing-based TEVGs, autologous scaffolds, selfassembled TEVGs, stem cells-based TEVGs and genetic modification tools have paved the way for constructing off-the-shelf TEVGs.

\section{D printing of TEVGs}

The production of 3D structures with complex geometry in TEVGs by printing is achieved with recent advances in 3D bioprinting. Biomaterials, living cells and chemical compounds are positioned layer-by-layer precisely in spatial distribution. ${ }^{39}$ As fabrication of microfluidic devices via the traditional method is tedious and labor-intensive, and requires complex machinery, 3D additive manufacturing-printing has recently emerged as an alternative to 3D-culture technologies. Indeed, the development of this technology has revolutionized the research in regenerative medicine.

Various 3D-printing approaches have been applied to produce vascularized engineered tissues. One common method is 3D stamping using polydimethylsiloxane as the supporting material. The 3D scaffold created by this method has a myriad of channels and holes. A vascular network is formed when the channels are lined with ECs. However, in addition to being expensive and tedious, 3D stamping hinders cell encapsulation. Therefore, nozzle-based 3D printers and laser-based stereolithographic bio-printing with better flexibility and versatility have gradually emerged as substitutes for labor-intensive stamping-based 3D printing. In recent years, 3D printing based on digital light processing has evolved to become a next-generation microfabrication technique. This new technique offers distinct advantages and is suitable for precise printing of complex 3D structures. Microscale continuous optical bioprinting is another type of modified digital 3D printing 


\begin{abstract}
microfluidics presents a robust platform that may be beneficial in stem-cell regenerative
\end{abstract} medicine.

A number of biomaterials have been surveyed for constructing TEVGs by 3D bioprinting. Fibrin gel promotes deposition of collagen in neonatal rat aortic smooth muscle cells (SMCs), but its low viscosity makes it inappropriate for 3D bioprinting. ${ }^{42,43}$ Collagen has been used as bioink for 3D bioprinting. ${ }^{44}$ However, long gelation time limits the application of collagen in 3D bioprinting. ${ }^{45}$ Concentrations of collagen less than 7.5 $\mathrm{mg} / \mathrm{ml}$ did not print successfully and collagen also spread over printing surface before gelation. ${ }^{44}$ Increasing collagen concentrations from $7.5 \mathrm{mg} / \mathrm{ml}$ to $12.5,15$ and $17.5 \mathrm{mg} / \mathrm{ml}$ showed improvement in the shape fidelity in a concentration-dependent manner. ${ }^{44}$ Some crosslink reagents such as riboflavin have been applied to enhance the stiffness of collagen-based hydrogels. ${ }^{46,47}$ The hydrolyzed derivative of collagen, gelatin, has been used in blend with other biomaterials as various bioinks establishing TEVGs. ${ }^{43}$ Alginate can be used as a good printable biomaterial, but lacks proper cell-attaching sites. ${ }^{48}$ These biomaterials require mixing with other biomaterials to improve their inherent properties for 3D bioprinting. Freeman et al. established TEVGs by rotary 3D bioprinting in a mixture of neonatal human dermal fibroblasts, gelatin and fibrinogen. Cell-laden bioink was composed of $7.5 \%$ gelatin and $10 \mathrm{mg} / \mathrm{ml}$ fibrinogen, and TEVGs were printed onto a polystyrene rod. After two-month culture, the burst pressure of TEVGs was $1110 \mathrm{mmHg} .{ }^{43}$ Gao et al. developed TEVGs containing ECs and SMCs by using triple-coaxial cell printing. ${ }^{49}$ The vascular tissue-specific bioink was composed with a mixture of vascular tissue-derived extracellular matrix and algination. ${ }^{50}$ The Pluronic F127 and bioinks laden with human umbilical vein endothelial cells (HUVECs) and human aortic SMCs were added to inner, middle, and outer-shell layers, respectively, through a triple-coaxial nozzle. These TEVGs were stimulated with pulsatile perfusion in a bioreactor. Average burst pressure of these 
TEVGs was $174 \pm 55 \mathrm{mmHg}$. These premature TEVGs were anastomosed into rat abdominal aorta for three weeks and the patency rate of these TEVGs was $100 \% .{ }^{49}$ Several factors influencing cell-laden bioink should be studied, including viscosity, stiffness and cell viability. These scaffold-free TEVGs generated by 3D bioprinting have been developed by different research groups. ${ }^{51,52}$

Norotte et al. used 3D bioprinting to construct scaffold-free TEVGs. Multicellular spheroids and cylinders of mesenchymal stem cells (MSCs) and fibroblasts were used as building blocks to construct TEVGs with defined cellular composition and geometry. It took several days to generate fused tubular structure after printing, and the resulting TEVGs further matured in a pulsed flow-stretch bioreactor. The geometry of this TEVG is limited due to the use of agarose as mold materials, which are removed manually. ${ }^{51}$ Itoh et al. built scaffold-free TEVGs by using a needle-array Bio-3D printer. HUVECs, human aortic SMCs and human normal dermal fibroblasts were mixed in the ratio of 4:1:5 and cocultured in ultra-low attachment plates to form multicellular spheroids (MCSs). The average size of MCSs was $615 \pm 51.3 \mu \mathrm{m}$. MCSs were transferred into a needle-array $(9 \times 9)$ robotically and a tubular structure was formed according to the pre-designed configuration. The resulting TEVG was perfused in a bioreactor for maturation, and implanted into the infrarenal abdominal aortas of nude rats. The TEVGs were patent and ECs covered the inner surface of these TEVGs after implantation. However, the mechanical property of these TEVGs was incomparable with native vessel. ${ }^{52}$ TEVGs can be assembled in a few weeks by means of 3D bioprinting. The period for manufacturing TEVGs has been decreased by using 3D printing, but the tensile strength of the resulting TEVGs needs improvement before clinical usage.

\section{Autologous hydrogels for vascular regeneration}

In recent decades, several types of scaffolds have been applied for the engineering of complex organs. The scaffolds support cell assembly and functionality, but biological scaffolding materials elicit host innate and acquired immune reactions in response to the immunological mismatch between the engineered graft and the host. ${ }^{53,54}$ Such immunological responses endanger the success of the engineered graft. ${ }^{55}$ To avoid this 
obstacle, the uses of autologous cells to prepare autologous ECM or personalized hydrogels offer promising solutions for scaffold fabrication. ${ }^{54,56}$ Autologous ECM scaffolds were prepared by combining autologous cells and a 3D template composed with a biodegradable polymer. ${ }^{54}$ After cell culture, the cellular components and the polymer template were removed to generate autologous ECM scaffold. ${ }^{54}$ Mouse autologous ECM scaffolds that were implanted into mice subcutaneously stimulated the lowest host immune response compared with allogeneic, xenogeneic and PLGA scaffolds. ${ }^{54}$ ECM scaffold derived from cultured cells lacks hierarchical porous structure to provide cells with guidance cues for directional migration and spatial organization. ${ }^{57}$ To improve the structure of ECM scaffold, Zhu et al. established ECM scaffolds with parallel microchannel in vivo. $^{57}$ Sacrificial templates, i.e. tubular form of aligned microfibers of poly $(\varepsilon-$ caprolactone) (PCL) wrapped around silicone rods, were implanted into rats subcutaneously for 4 weeks and the inter-fiber space was occupied by fibrous tissues. ${ }^{57}$ Sacrificial templates and cellular components were subsequently removed. ECM scaffolds were anastomosed as end-to-end interpositional arterial grafts for artery regeneration of the rat abdominal artery. The burst pressure of these scaffolds was $1489 \pm 208 \mathrm{mmHg}$, similar to that of human saphenous veins. The suture retention of these TEVGs was 244.73 \pm 30.59 gram force (gf). In physiological analysis, the patency ratio of these TEVGs was $100 \%$ for three months, these TEVGs could respond to vasomotor agonists and vasodilators in a way partially similar to native arteries, and no platelet aggregates or thrombi were observed in the inner of these TEVGs. ${ }^{57}$ The decellularized autologous ECM scaffolds displayed better biocompatibility and immuno-modulation to reduce the risk of rejection or provoking foreign body response. ${ }^{58}$

Fibrin gel can be harvested from the patient's own plasma and used as autologous scaffold without the risk of foreign body response. ${ }^{36,59}$ Gui et al. established TEVGs by entrapping a 50:50 mixture of bovine SMCs and neonatal human dermal fibroblasts in fibrin gels. These TEVGs were grown in a pulsatile bioreactor for 30 days. An average burst pressure of TEVGs was $913.3 \pm 150.1 \mathrm{mmHg}$, and the corresponding suture retention 53.3 \pm 15.4 gf. $^{36}$ In contrast to fibrin-based TEVGs, the burst pressures of native saphenous vein and internal mammary artery were $1599 \pm 877 \mathrm{mmHg}$ and $3196 \pm 1264 \mathrm{mmHg} .{ }^{60}$ The 
suture retention of native internal mammary artery was $138 \pm 50$ gf. $^{60}$ Several groups tried to generate TEVGs by means of fibrin-based scaffolds, but the vessel strength of these TEVGs remained to be improved. ${ }^{34,36,61,62}$

Personalized hydrogels derived from ECM of omental tissues displayed decreased immune responses in a small-animal model. ${ }^{56}$ Incorporation of personalized hydrogels with autologous induced pluripotent stem cells (iPSCs) is feasible in functional adipogenic, cardiac, cortical and spinal cord tissue implants. ${ }^{56}$ The cardiomyocytes and ECs differentiating from autologous iPSCs can be combined with personalized hydrogel to form bioinks. By using 3D-printing technology together with computerized tomography identifying the orientation of blood vessels in an individual's heart, a mathematical model can be used to design the supplemented blood vessels, and a cellularized human heart can be potentially printed. ${ }^{63}$ The proper orientation of blood vessels is a key factor in such tissue engineering approaches. The personalized vascular tissue can provide ideal engineering tissue blocks without host immune response in patients (Fig. 3).

Whole ECM extracted from tissues has been used as hydrogel scaffolds ${ }^{33}$ while invasive surgical requirement and rare availability of autologous hydrogel limit its application. There are still many obstacles to the use of autologous materials for developing personalized organs while it is relatively feasible to generate small-diameter TEVGs.

\section{Advancements in self-assembled TEVGs}

Biological scaffold materials composed of mammalian ECM and synthetic scaffold materials are commonly used for tissue engineering. ${ }^{32}$ The use of biological (allogeneic or xenogeneic) and synthetic scaffold materials induces the innate and acquired host immune responses. $^{64,65}$ The scaffold-free methods are recently developed based on tissue engineering by self-assembly. ${ }^{66}$

L'Heureux et al. used cellular sheets to construct TEVGs without any scaffold material. Human SMCs and fibroblasts were cultured in flasks to form sheets with cells and ECM. Cellular sheets of human SMCs and fibroblasts were stripped from culture flasks. Sheets of fibroblasts were wrapped around to form a tubular structure and dehydrated to 
generate an acellular inner membrane. Inner membrane was rolled with sheets of human SMCs and placed in a bioreactor with stimulation of luminal flow of culture medium and mechanical support. The construct was rolled with sheets of fibroblasts. ECs was seeded into the inner lumen of this construct. ${ }^{67}$ This TEVG was composed of three distinct layers including tunica intima (ECS), tunica media (SMCs) and tunica adventitia (fibroblasts). ${ }^{68}$ The media layer of SMCs displayed contractile property. ${ }^{69}$ The burst pressure of the resulting TEVGs was 2,594 $\pm 501 \mathrm{mmHg}^{67}$

The limited lifespan of SMCs is a major obstacle to establishing autologous human TEVGs. ${ }^{70}$ The cell-sheet-based TEVG without SMCs was further developed. The TEVGs were constructed with human skin fibroblasts isolated from elderly patients (age $65 \pm 8$ years), and exhibited burst pressure of more than $3,000 \mathrm{mmHg}$, similar to that of human arteries. The suture retention strength of TEVGs was $162 \pm 15$ gf. The TEVGs were implanted into both nude rats and immunosuppressed cynomolgus macaques with the patency rates of TEVGs reaching $85 \%$ in rats (up to 225 days) and $100 \%$ in macaques (up to 8 weeks). ${ }^{71}$ Furthermore, a similar strategy was used to construct autologous TEVGs from patients diagnosed with arteriovenous shunt failure. After transplantation into ten patients, these TEVGs functioned well up to 3 months with average burst pressure of $3,400 \pm 849$ mmHg. ${ }^{72}$ This clinical trial demonstrated that autologous self-assembled vascular graft could be used in clinics with long-term patency (80\%) despite two reports of graftassociated failure. ${ }^{73}$ In view of the long time used for generating autologous cellular sheets, ${ }^{67,71}$ an allogeneic, nonliving TEVG serving as the brachial-axillary arteriovenous shunts for hemodialysis access may provide another feasible approach. The inner membranes were generated by cellular sheets of fibroblasts isolated from donors and stored at $-80^{\circ} \mathrm{C}$ for a long period ( 6 to 13 months). Autologous ECs were then seeded in the graft before being implanted into patients. Unfortunately, numerous accounts of graft failure were observed as a result of stenosis, occlusion induced by automobile accident, systemic infection or thrombosis at different time points. ${ }^{74}$ This study suggests a possibility of premade vascular grafts in clinical use while many conditions should be further improved. 
To shorten the production time required for establishing self-assembled TEVGs, Bornstädt et al. used a clinically approved biodegradable tissue glue to facilitate the maturation of TEVGs. Bi-level cell sheets composed by human aortic SMCs and skin fibroblasts were wrapped around a needle to produce tubular vessel constructs. Flexible glue membranes were wrapped around cell sheet constructs. A glue membrane-stabilized construct was perfused and endothelialized in a bioreactor immediately. After 14 days of in vitro perfusion, these resulting TEVGs exhibited burst pressure of more than $500 \mathrm{mmHg}$. These engineered vascular conduits were used as femoral artery interposition grafts implanted into nude rats. Eight weeks after implantation, the patency rate of implanted conduits was $100 \%$ and the burst pressure of TEVGs reached $946 \mathrm{mmHg}$, similar to that of native rat femoral arteries. The production time of self-assembled TEVGs was reduced to two weeks, thereby acceptable for clinical applications. ${ }^{75}$

\section{Novel Cell Sources for TEVGs}

The use of various stem-cell types for in vivo vascular regeneration and ex vivo tissue engineering has been extensively investigated. Many studies have shown the successful development of TEVGs by using adult cells, stem cells or progenitor cells, and have been reviewed by Pashneh-Tala et al. and Elliot et al. ${ }^{5,17}$

Several attempts have been made in recent years to elucidate the distinct mechanisms by which injured blood vessels are ultimately repaired. For example, the dynamics and mechanisms by which embryonic vascular SMCs facilitate arterial repairs in adults were recently examined. ${ }^{76}$ The smooth muscle progenitor cells expressing CD146 emerge during embryogenesis and reside at arterial branch sites after birth. ${ }^{76}$ During vascular repairing, $\mathrm{CD} 146^{+}$vascular SMCs proliferate to regenerate arterial wall in a wireinduced injury model. In an anastomosis model, severe injury induces existing SMC death, leaving behind ECM scaffold in arterial wall. A small population of adventitial tissue cells expressing stem cell antigen 1 (Sca1; Ly6A/E), CD44, CD34 and GLI1 is capable of vascular SMC differentiation. ${ }^{76,77}$ This matrix is repopulated by cells that differentiate into new SMCs. ${ }^{76}$ Different cell populations regulate vascular wall remodeling in response to injury. Adventitial stem cells could thus be successfully seeded into scaffolds during stem-cell 
engineering to improve the structural integrity of arterial conduits before transplantation into animals.

Generation of ECs and SMCs from human pluripotent stem cells. The number of cell divisions is limited, and cellular senescence accompanying the failure response to exogenous growth factors is observed in human primary ECs and endothelial progenitor cells (EPCS). ${ }^{78}$ The major obstacles to the use of vascular cells for generating tissueengineered grafts were the sources and amount of cells. Human pluripotent stem cells (hPSCs), such as human embryonic stem cells (hESCs) and iPSCs, are a potential solution to this limitation. ${ }^{79}$ The properties of self-renewal and multi-lineage differentiation capabilities of hPSCs enable them to become a good source of vascular cells. iPSC-ECS show a divergent capacity to form capillaries when compared to HUVECs. ${ }^{80}$ However, to avoid teratoma formation, the hPSCs must reach a particular differentiation stage before therapeutic use. ${ }^{81}$

Stem cell-based generation of vascular cells provides an unlimited cell source for producing TEVGs. ${ }^{81-83}$ Generali et al. generated autologous endothelialized TEVGs from blood-derived iPSCs. Human peripheral blood mononuclear cells (PBMCs) were harvested from donor's peripheral blood and reprogrammed to iPSCs by viral vectors. Blood-derived hiPSCs were differentiated to SMCs and ECs. hiPSC-derived SMCs were seeded onto tubular scaffolds and cultured under pulsatile flow. hiPSC-derived ECs were seeded into the lumen of TEVGs. The resulting TEVGs displayed architecture similar to that of smallcaliber vessels. This is the first report that TEVGs have been generated from PBMC-derived iPSCs. ${ }^{83}$ Gui et al. established TEVGs using hiPSC-derived SMCs. The hiPSCs were generated from human neonatal fibroblasts isolated from a healthy female donor. hiPSCs were differentiated to SMCs via the approach of embryoid bodies (EB). hiPSC-SMCs were seeded onto tubular scaffold (built using the synthetic substrate polyglycolic acid) and cultured in bioreactors. The resulting TEVGs were implanted into nude rats as abdominal aorta interposition grafts for two weeks and the patent rate of these TEVGs was $100 \%{ }^{84}$ However, these hiPSC-derived TEVGs displayed low mechanical strength that caused significant radial dilation after implantation. Recently, Luo et al. modified Gui's protocol to establish TEVGs with advanced mechanical strength. They improved the procedures of EB 
formation, SMC differentiation and hiPSC-TEVG maturation. The burst pressure of the resulting TEVGs was $1419.0 \pm 174.4 \mathrm{mmHg}$, and the corresponding suture retention strength $157.5 \pm 16.5$ gf. hiPSC-TEVGs were implanted into nude rats as abdominal aorta interposition grafts for 30 days. All grafts were patent in rats. No dilation, elongation or wall thickening was observed in these grafts. However, slight thrombosis was noticed in some TEVGs. The endothelial lining could reduce thrombosis. ${ }^{85}$ These studies demonstrate that hiPSC can be a good source to construct TEVGs. The clinical application of hiPSCderived TEVGs may be realized in the near future.

\section{Nanotechnology-based Enhancement and Preclinical Monitoring of TEVGs}

Nanotechnology uses synthetic nanoparticles with sizes from 10 to $100 \mathrm{~nm}$, which can be made in solid or colloidal forms. Their small size with high surface area makes it feasible to conjugate them with many different ligands and enables them to penetrate tissues or cells freely. ${ }^{86-88}$ The application of nanoparticles in vascular tissue engineering has the potential to overcome some unsolved problems such as the difficult fabrication of vascular grafts to maintain tubular structures, and TEVG monitoring. ${ }^{88}$ Magnetic resonance imaging (MRI) offers the best soft tissue contrast among non-invasive imaging modalities used in clinical settings. However, the structural similarity between native vessels and TEVGs hampers the application of MRI in TEVG monitoring. Nanoparticles can be used as contrast reagents to label TEVGs and nanoparticle-labeled TEVGs can be distinguished from native vessels by MRI. ${ }^{89}$

\section{Improving the property of scaffolds}

Fibronectin-coated scaffold incorporated with gold nanoparticles (FN-AuNP) has been developed to establish MSC-bearing TEVGs. The FN-AuNP displayed higher hydrophilicity and pyrolytic temperature than fibronectin scaffold. The addition of AuNP stabilized scaffold and enhanced cell attachment. MSCs in the FN-AuNP-coated catheter displayed higher antithrombotic property and differentiation efficiency toward SMCs and ECs than that in the fibronectin-coated catheter in vivo. ${ }^{90}$ Implant-associated infection is a major cause of graft failure. Madhavan et al. incorporated $0.1 \%$ silver nanoparticles on $\mathrm{PCL}$ scaffold and demonstrated that this scaffold was antimicrobial while non-cytotoxic to ECs. 
However, higher concentration of silver nanoparticles could induce EC death. ${ }^{91}$ The concentration of silver nanoparticles should be optimized between levels required to achieve antimicrobial and non-cytotoxic property.

\section{Fabrication of tissue-engineered tubular constructs}

Ito et al. introduced magnetic cationic liposome (average size $150 \mathrm{~nm}$ ) into ECs, SMCs and fibroblasts. These magnetic nanoparticle-labeled cells were cultured in ultralowattachment plates under a magnetic field to form a cell sheet. These magnetically labeled cell sheets were rolled onto a cylindrical magnet to form a tubular structure. ${ }^{92}$ Magnetic force-based TEVGs could be developed in several days, but poor mechanical strength was observed in these TEVGs. Shimizu et al. used the same magnetic cationic liposome to label human SMCs and dermal fibroblasts. These magnetically labeled SMCs and dermal fibroblasts were subsequently seeded onto decellularized porcine common carotid artery inserted with cylindrical magnet in its lumen. More than $90 \%$ SMCs and $70 \%$ dermal fibroblasts were successfully seeded onto the scaffold. From histological study, SMCs and dermal fibroblasts established two distinct layers on decellularized porcine common carotid artery. ${ }^{93}$

\section{Tracing TEVGs in vivo}

The traditional techniques to monitor TEVGs in vivo are often invasive, for example, taking biopsy from the site implanted and sacrificing TEVG-implanted animals to collect data. ${ }^{94}$ Developing noninvasive methods to access implanted grafts could monitor realtime changes to facilitate the design of improved TEVGs. ${ }^{94,95}$ Magnetic nanoparticles are widely used in tracking cells in vivo and in vitro by MRI. Magnetic nanoparticles interact with neighboring protons in water molecules to enhance the image contrast when a magnetic field is applied. ${ }^{96}$ Nelson et al. labeled human aortic SMCs with poly-L-lysinecoated ultrasmall superparamagnetic iron oxide (USPIO) nanoparticles. USPIO-labeled cells were seeded onto a biodegradable scaffold and cultured for six days. Human aortic ECs were seeded into the lumen of TEVGs. The resulting TEVGs were implanted into severe combined immunodeficient (SCID) mice as aortic interposition grafts. T2-weighted images demonstrated USPIO-labeled TEVGs displayed shaper borders than control TEVGs. ${ }^{95}$ 
Furthermore, they labeled murine macrophages with USPIO nanoparticles. USPIO-labeled macrophages were seeded onto biodegradable tubular scaffolds. Cell-loaded scaffold were implanted into SCID mice as inferior vena cava interposition grafts, and the dynamic change of USPIO-labeled macrophages could be assessed in vivo by MRI. ${ }^{94}$

Besides labeling cells, nanoparticles can be used to label scaffolds to assess dynamic changes of TEVGs in vivo. USPIO nanoparticles were incorporated into polyvinylidene fluoride (PVDF)-based textile materials. USPIO-labeled PDVF then served as tubular molds to culture with SMCs and fibroblasts in fibrin gel. ECs were seeded into the lumen of TEVGs in a bioreactor. The resulting TEVGs were implanted into sheep as arteriovenous shunts. During bioreactor cultivation and after animal implantation, the resulting TEVGs were assessed by T1-, T2-, and T2*-MRI. USPIO label on TEVGs improved MRI visualization both in vitro and in vivo. ${ }^{97}$ Multimodal imaging approaches to assessing TEVGs can support realtime clinical decision-making. Wolf et al. established USPIO-labeled TEVGs in a similar way and implanted the resulting TEVGs into sheep as carotid artery for eight weeks. The resulting TEVGs could be delineated from native arteries and precisely localized by MRI. ${ }^{18}$ F-fluordeoxyglucose uptake, a sign of local inflammation, was analyzed by positron emission tomography coupled with computed tomography in parallel with MRI. ${ }^{89}$ Obtaining accurate and complete information by multimodal imaging can facilitate the application of TEVGs in the clinical settings.

However, one limitation of using nanoparticles to facilitate the assessment of TEVGs is the long-term stability of nanoparticles. ${ }^{95}$ The half-life of iron oxide nanoparticles in rat liver was 8 days for dextran-coated materials, 10 days for carboxydextran materials, 14 days for unformulated oxidized-starch, and 29 days for formulated oxidized-starch. ${ }^{98}$ Several modifications of iron oxide nanoparticles by coating with different molecules displayed lower intracellular biodegradation rate in human MSCs. ${ }^{99}$ These modified magnetic nanoparticles could be used in long-term TEVG tracking in vivo.

\section{Preclinical Evaluation of Engineered Blood Vessels}

Before TEVGs are used in humans, preclinical in vivo evaluation is required to estimate their function and biocompatibility. During preclinical in vivo examination, TEVGs 
will be modified and improved step by step to ensure that TEVGs meet all design requirements. ${ }^{100}$ Several preclinical studies have focused on optimizing the vascular conduits in different animal models. Analysis of the transplantation effects of small grafts (ranging between 1 and $4 \mathrm{~mm}$ in diameter) in small animals such as rabbits and rodents (rats and mice) revealed high variability and activation of innate immune system. To overcome these problems, a SCID mouse model was developed in $1983 .{ }^{101}$ Several smalldiameter vascular conduits were constructed using decellularized ovine arterial tissue, silastic tubing, polyurethane grafts or polytetrafluroethylene grafts, and then surgically implanted as an aortic interposition graft in the SCID mice, and all displayed excellent patency up to 35 days. ${ }^{102}$ Small animals provide indispensable models for some diseasespecific microenvironments and are considered to be suitable and relatively cheap for small-scale evaluation of newly developed TEVGs and biomaterials. However, rodents possess distinct regeneration characteristics with a faster rate of graft endothelialization when compared to humans, particularly elderly subjects. This makes it difficult to interpret the clinical utility of TEVGs from rodent models.

With regard to large animals, most of the studies of scaffold-based TEVGs have been performed using canine, ovine or porcine models. ${ }^{103} \mathrm{~A}$ groundbreaking experiment performed on dogs over a decade ago demonstrated regenerating vascular tissues from bone marrow (BM)-derived stem cells. ${ }^{104}$ Consequently, the graft showed excellent patency with no visible pathological symptoms two months after transplantation into the vena cava of the same dog. ${ }^{104}$ The successful transplantation and long-term grafting suggest that autologous stem cells can be successfully manipulated in suitable biocompatible scaffolds to bridge in vivo vascular openings. Lambs/sheep are often favored over the porcine models since these animals display a coagulation mechanism comparable to that of humans. Experiments conducted with different cell types (ECs, SMCs, EPCs and myofibroblasts) have revealed that bio-scaffolds with different material compositions (collagen, fibrin, hyaluronan, polyglycolic acid or decellularized artery) have good biocompatibility. In summary, the choice of test animals and evaluation of experimental results analyzing the effects of transplanted TEVGs in different preclinical animal models require several considerations, which include the size of the tissue- 
engineered graft, the transplant location, the long-term patency (e.g., immunogenicity interference), and the hematological response (e.g., coagulation or thrombus formation).

Pre-clinical evaluation in small- or large-animal models may effectively predict the success of vascular grafts if tested in clinical trials, and approaches to evaluating the patency of TEVGs with long-term follow-up are well established. ${ }^{16,38,105,106}$ Histological and immunocytochemical analyses are standard ex vivo procedures that provide endpoint information, including the structure and ECM composition of engineered vasculature compared to native vessels. Both types of analyses with specific markers are also useful for the identification of transplanted versus endogenous cell populations. Numerous imaging techniques, such as angiography, Doppler ultrasound, echocardiography, computerized tomographic scanning and MRI enable evaluation of TEVGs in vivo in real time. ${ }^{107}$ Moreover, a nanotechnology-based non-invasive strategy has recently been developed for real-time serial monitoring of cell-based TEVGs in vivo. ${ }^{87}$ Beyond molecular imaging data, in vivo parameters, such as compliance and pulsatile flow, are critical criteria that can be effectively applied to determine the success of tissue-engineered blood vessels in clinical trials.

We summarize here the updated progress of cell-based TEVGs from in vitro, in vivo to preclinical evaluation (Table 1). The method for establishing preendothelialized synthetic grafts was improved gradually by pre-coating the grafts with fibrin glue mixed with human fibronectin and fibrinolysis inhibitors. ${ }^{108-110}$ The preendothelialized fibrin gluecoated expanded PTFE (ePTFE) protheses were implanted into dogs and all grafts remained patent. ${ }^{111}$ The autologous in vitro endothelization of ePTFE grafts were applied in patients who had no saphenous vein available for bypass surgeries, and the patency rate of preendothelialized grafts was better. ${ }^{14,112}$ The tissue-engineered ovine pulmonary artery autografts generated from ovine artery and synthetic biodegradable (PCL/PLA, where PLA is poly-lactic acid) tubular scaffolds functioned well in the pulmonary circulation in an ovine model. ${ }^{113}$ This model was applied in a patient with a single right ventricle and pulmonary atresia, and an autograft of pulmonary artery established from a peripheral vein was completely patent. ${ }^{114}$ The tissue-engineered vascular autografts constructed by BM cells and biodegradable (PCL/PLA) scaffold were implanted into the inferior vena cava 
of dogs and no obstruction was observed in these implanted dogs. ${ }^{115}$ The BM cell-derived autografts were successfully used in patients for extracardiac total cavopulmonary connection or the repair of congenital heart defects, without any complication observed. ${ }^{116}$ The in vivo assessment of human self-assembled TEVGs in rat and macaque models demonstrated high patency rates after implantation. ${ }^{71}$ The human self-assembled TEVGs were applied in patients with shunt failure and the long-term patency of selfassembled TEVGs was high in patients. ${ }^{74}$ Several novel strategies to establish TEVGs are proposed recently, but it is necessary to conduct in vitro, in vivo and preclinical evaluation before ultimate clinical application.

\section{Conclusion and Future Perspectives}

As the number of patients requiring replacement therapies continues to increase, stem cell-based intervention provides a potential solution to both current graft replacement challenges and future vascular support in solid organ regeneration or replacement. Selection of stem-cell therapy for regeneration or replacement purposes is partly attributed to tissue shortage and incompatible tissue source. It is widely accepted that, when compared to 2D culture systems, 3D culture and additive-manufacturing methods may allow better evaluation of physiological and pathological events with greater accuracy. The search for compatible natural or synthetic graft materials that can be effectively used to manage various problems associated with vascular disease and organ failure has therefore drawn great interest. The debate concerning the effectiveness of natural and synthetic materials for 3D platforms is expected to persist while researchers continue to evaluate the merits and limitations of different scaffolds. Another potential challenge is the properties of the cells that eventually occupy these scaffolds.

hPSCs provide a good cell source with unlimited proliferation capacity and an ability to differentiate into all human cell types. While stem cells can be engineered to produce specific tissues in vitro, there are concerns that the properties of the newly generated tissues may hinder their transplantation into living animals with future complications, particularly those due to unintended mutation effects. Autologous hPSCs derived from a patient's own cells will be the best source for cell therapy, but it is a much more 
complicated customer-based model. The whole procedures from isolating cells from patients, inducing PSCs from autologous cells, removing disease-causing mutations and differentiating them into specific cell lineages are time-consuming. Stem cells from individuals are theoretically capable of regenerating structures with limited complications, but the current lack of successful stem-cell therapy in human tissue engineering may be due to under-appreciated micro-environmental differences between cultured cells and living systems. Most recently, gene-manipulating strategies can provide suitable sources from stem/progenitor cells with improved functions such as mature vascular differentiation, hypoimmunogenic property and expandable without tumorigenicity.

\section{Genetically modified cells}

Genetically modified cells may be beneficial in fabricating TEVGs. They are generated by the introduction of genetic material (DNA or RNA) into cells to: i) replace a diseasecausing gene; ii) inactivate a mutated gene; iii) transdifferentiate some specific cell lineages; or iv) express growth factors for cell expansion. ${ }^{117}$ For example, vascular grafts engineered from MSCs with endothelial nitric oxide synthase could inhibit neointimal and thrombus formation. ${ }^{118}$ Rat SMCs that were transfected with protein kinase G exhibited higher expression of the contractile protein smooth muscle actin and responded to mechanical stimulation better in tubular collagen type I gels. ${ }^{119}$

Synthetic modified mRNA. Depending on the types of vector used, the genetic material of interest is either integrated or not integrated into a chromosome. ${ }^{120}$ For clinical purposes, synthetic modified mRNA (modRNA)-based gene regulation is a promising tool to control engineered stem cells without causing any insertion mutation when compared with plasmid-based or viral vector-based methods. ${ }^{121,122}$ Currently, researchers are studying the possible use of modRNA-encoded transcription factors to manipulate cell fate conversion for use in tissue engineering. ${ }^{123,124}$ Fibroblasts were transfected with modRNAs encoding OCT3/4, SOX2, KLF4 and C-MYC, and reprogrammed as iPSCs. ${ }^{122,125}$ As a less immunogenic and more stable form of RNA without the risk of insertional mutagenesis, modRNAs should be a powerful tool in vascular tissue engineering, and may be used in clinical setting in the near future. ${ }^{123,124}$ The dermal fibroblasts were successfully 
reprogrammed into functional EPCs by transfecting with ETV2-encoding modRNA in combination with hypoxia treatment. ${ }^{126}$ In addition, induced differentiation of hESCderived $|s|^{+}$cells into ECs has also been achieved by transfecting the modRNA encoding VEGFA. ${ }^{127}$ hPSCs were also differentiated into typical endothelial phenotype by delivery of modRNA encoding ETV2. ${ }^{128}$ However, the modRNA-based reprogramming protocol is complicated and laborious. ${ }^{123}$ It requires multiple transfections in cell fate conversion. ${ }^{123,126}$ The high cost of modRNAs and their sensitivity to heat and nuclease limit their application in tissue engineering. ${ }^{123}$

CRISPR/Cas9-mediated gene editing. Genome editing, which involves the alteration or modification of the genome in living cells, has been an indispensable tool in research involving 3D culture systems. The nuclease-directed gene-editing method has emerged as a superior tool for manipulating the genomes of organisms. In particular, clustered regularly interspaced short palindromic repeats (CRISPR)/CRISPR-associated protein-9 nuclease (CRISPR/Cas9) technology has emerged as the best genome-editing tool over the few past years owing to its relative ease of use, efficiency and robustness. ${ }^{129}$ This system has the potential to achieve site-specific cleavage and recombination of any target genomic region containing a specific short sequence known as protospacer adjacent motif sequence. $^{130}$ This system has the potential to achieve site-specific cleavage and recombination of any target genome. ${ }^{130}$ Currently, CRISPR/Cas9 can apply in gene correction, activation and knockout. ${ }^{129}$

The autologous iPSCs solved the problem of immunogenic rejection associated with the transplantation of allogeneic cells. However, disease-causing gene in autologous iPSCs should be ideally corrected or modified before therapy. Double-stranded DNA breaks (DSBs) created by CRISPR/Cas9 are repaired by non-homologous end joining (NHEJ) or homology-directed repair (HDR). ${ }^{131,132}$ HDR can be used to incorporate the DNA fragment between two homologous arms to generate a precise DNA deletion, substitution or insertion, and hence correct a diseasing-causing gene. Unfortunately, the efficiency of HDR in hPSCs subjected to DSBs is only $0.1-1 \%$ after creating DSBs. ${ }^{133-135}$ The low efficiency in editing hPSCs is due to low cell viability. Currently, transient $B C L-X L$ overexpression in 
hPSCs can enhance the genome-editing efficiency via CRISPR/Cas9. ${ }^{136}$ This strategy may increase the use of autologous iPSCs in future clinical trials.

\section{Hypoimmune allogeneic cells}

When autologous cells are not available for treating patients, alternative allogeneic cells that will not elicit an immune response are a good resource for tissue engineering. Generating and storing immunocompatible cells are now being developed in several laboratories. Merola et al. ablated both $\beta_{2}$-microglobulin and class II transactivator in cordblood endothelial colony-forming cells by using CRISPR/Cas9. The expression of class I and II major histocompatibility complex (MHC) were eliminated in the resulting ECs. MHCeliminated ECs did not trigger humoral and cellular immune responses, and could be used as a cell source of TEVGs. ${ }^{137}$ The human leukocyte antigen B (HLA-B) knockout iPSCs via CRISPR/Cas9 display less immunogenicity and are well suited to stem-cell allotransplantation. $^{138}$ The bank of HLA-homologous iPSC lines for allogeneic transplantation is a potentially useful source for tissue engineering. ${ }^{139,140}$ Ablation of HLAA/-B/-C and HLA class II, and expression of the immunomodulatory factors (PD-L1 and HLA$\mathrm{G}$ and the macrophage signal CD47) in hPSCs all contribute to a hypoimmunogenic display in vitro and in vivo. ${ }^{141}$ L'Heureux et al. have demonstrated that allogeneic grafts produced from donors' fibroblasts were safe for implantation into patients without eliciting the immune response. ${ }^{74}$ These strategies using hypoimmune cells and allogeneic grafts may generate off-the-shelf universal cell products that can be used to treat a large pool of patients (Fig. 4).

Allogeneic hPSCs produced from non-self donors can be an alternative source with several advantages, such as industrial scalability, lower cost for manufacturing and free of disease-causing mutations. However, the host's immunologic rejection to allogeneic hPSCs restricts further applications. Using genetic modification tools, the allogeneic hypoimmunogenic hPSCs can be the universal cell source for transplantation into any host. The allogeneic hypoimmunogenic hPSCs have both practicality and commercial potential to create off-the-shelf TEVGs. The universal TEVGs available to any patient are very appealing for clinicians. The combination of genetic modification tools and stem cells 
provides an attractive strategy to generate universal cell source for the vascular tissue engineering. However, for clinical applications, numerous questions still remain unanswered. Is it safe to remove immune recognition molecules that are important against cancerous and pathogen-infected cells? Will multiple gene deletions increase an undesired oncogenic risk? Will hypoimmunogenic cells induce any unpredictable immune response? Further studies in immunology and in vivo testing will provide a better design for the application of hypoimmunogenic cells. The generation of ideal ECM or scaffolds with adequate quantities of cytokines, hormones and other biomolecules may represent one of the final hurdles in race to successfully generate biocompatible vascular grafts at a microscopic level and finally at a whole-organ level.

\section{Acknowledgments}

Grant support for C.L.H.: National Natural Science Foundation of China (no. 31701192), and PolyU internal fundings (4-BCEQ, G-UAFL and 1-ZVM1). Grant support for S.P.Y: PolyU internal funding (99QP). Salary support for S.G.C.: PolyU Postdoctoral Fellowships Scheme (1-YW3K).

\section{Disclosure Statement}

There are no conflicts of interest to declare. 


\section{References}

1. Song, H.G., Rumma, R.T., Ozaki, C.K., Edelman, E.R., and Chen, C.S. Vascular Tissue Engineering: Progress, Challenges, and Clinical Promise. Cell Stem Cell 22, 340, 2018.

2. Schaftenaar, F., Frodermann, V., Kuiper, J., and Lutgens, E. Atherosclerosis: the interplay between lipids and immune cells. Curr Opin Lipidol 27, 209, 2016.

3. Turk-Adawi, K., Sarrafzadegan, N., Fadhil, I., et al. Cardiovascular disease in the Eastern Mediterranean region: epidemiology and risk factor burden. Nat Rev Cardiol 15, 106, 2018.

4. Kasapis, C., and Gurm, H.S. Current approach to the diagnosis and treatment of femoral-popliteal arterial disease. A systematic review. Curr Cardiol Rev 5, 296, 2009.

5. Pashneh-Tala, S., MacNeil, S., and Claeyssens, F. The Tissue-Engineered Vascular Graft-Past, Present, and Future. Tissue Eng Part B Rev 22, 68, 2016.

6. Cuminetti, G., Gelsomino, S., Curello, S., Lorusso, R., Maessen, J.G., and Hoorntje, J.C. Contemporary use of arterial and venous conduits in coronary artery bypass grafting: anatomical, functional and clinical aspects. Neth Heart J 25, 4, 2017.

7. Wang, X., Lin, P., Yao, Q., and Chen, C. Development of small-diameter vascular grafts. World J Surg 31, 682, 2007.

8. Chlupac, J., Filova, E., and Bacakova, L. Blood vessel replacement: 50 years of development and tissue engineering paradigms in vascular surgery. Physiol Res 58 Suppl 2, S119, 2009.

9. Sundaram, S., One, J., Siewert, J., et al. Tissue-engineered vascular grafts created from human induced pluripotent stem cells. Stem Cells Transl Med 3, 1535, 2014.

10. Dahl, S.L., Kypson, A.P., Lawson, J.H., et al. Readily available tissue-engineered vascular grafts. Sci Transl Med 3, 68ra9, 2011.

11. de Vries, M.R., Simons, K.H., Jukema, J.W., Braun, J., and Quax, P.H. Vein graft failure: from pathophysiology to clinical outcomes. Nat Rev Cardiol 13, 451, 2016.

12. Chang, W.G., and Niklason, L.E. A short discourse on vascular tissue engineering. NPJ Regen Med 2, 2017.

13. Desai, M., Seifalian, A.M., and Hamilton, G. Role of prosthetic conduits in coronary artery bypass grafting. Eur J Cardiothorac Surg 40, 394, 2011. 
14. Deutsch, M., Meinhart, J., Zilla, P., et al. Long-term experience in autologous in vitro endothelialization of infrainguinal ePTFE grafts. J Vasc Surg 49, 352, 2009.

15. Pasic, M., Muller-Glauser, W., von Segesser, L., Odermatt, B., Lachat, M., and Turina, M. Endothelial cell seeding improves patency of synthetic vascular grafts: manual versus automatized method. Eur J Cardiothorac Surg 10, 372, 1996.

16. Skovrind, I., Harvald, E.B., Juul Belling, H., Jorgensen, C.D., Lindholt, J.S., and Andersen, D.C. Concise Review: Patency of Small-Diameter Tissue-Engineered Vascular Grafts: A Meta-Analysis of Preclinical Trials. Stem Cells Transl Med 8, 671, 2019.

17. Elliott, M.B., and Gerecht, S. Three-dimensional culture of small-diameter vascular grafts. J Mater Chem B 4, 3443, 2016.

18. Lovett, M., Lee, K., Edwards, A., and Kaplan, D.L. Vascularization strategies for tissue engineering. Tissue Eng Part B Rev 15, 353, 2009.

19. Carrabba, M., and Madeddu, P. Current Strategies for the Manufacture of Small Size Tissue Engineering Vascular Grafts. Front Bioeng Biotechnol 6, 41, 2018.

20. Chan, B.P., and Leong, K.W. Scaffolding in tissue engineering: general approaches and tissue-specific considerations. Eur Spine J 17 Suppl 4, 467, 2008.

21. Freed, L.E., Vunjak-Novakovic, G., Biron, R.J., et al. Biodegradable polymer scaffolds for tissue engineering. Biotechnology (N Y) 12, 689, 1994.

22. Gui, L., Zhao, L., Spencer, R.W., et al. Development of novel biodegradable polymer scaffolds for vascular tissue engineering. Tissue Eng Part A 17, 1191, 2011.

23. Zhang, X., Wang, X., Keshav, V., et al. Dynamic culture conditions to generate silkbased tissue-engineered vascular grafts. Biomaterials 30, 3213, 2009.

24. Prasadh, S., and Wong, R.C.W. Unraveling the mechanical strength of biomaterials used as a bone scaffold in oral and maxillofacial defects. Oral Science International 15, 48, 2018.

25. Ciardelli, G., Chiono, V., Vozzi, G., et al. Blends of poly-(epsilon-caprolactone) and polysaccharides in tissue engineering applications. Biomacromolecules 6, 1961, 2005.

26. Gunatillake, P.A., and Adhikari, R. Biodegradable synthetic polymers for tissue engineering. Eur Cell Mater 5, 1, 2003. 
27. Spicer, C.D. Hydrogel scaffolds for tissue engineering: the importance of polymer choice. Polymer Chemistry 11, 184, 2020.

28. Gui, L., Muto, A., Chan, S.A., Breuer, C.K., and Niklason, L.E. Development of decellularized human umbilical arteries as small-diameter vascular grafts. Tissue Eng Part A 15, 2665, 2009.

29. Matassi, F., Nistri, L., Chicon Paez, D., and Innocenti, M. New biomaterials for bone regeneration. Clin Cases Miner Bone Metab 8, 21, 2011.

30. Szymanska, E., and Winnicka, K. Stability of chitosan-a challenge for pharmaceutical and biomedical applications. Mar Drugs 13, 1819, 2015.

31. Oryan, A., Kamali, A., Moshiri, A., Baharvand, H., and Daemi, H. Chemical crosslinking of biopolymeric scaffolds: Current knowledge and future directions of crosslinked engineered bone scaffolds. Int J Biol Macromol 107, 678, 2018.

32. O'Brien, F.J. Biomaterials \& scaffolds for tissue engineering. Materials Today 14,88 , 2011.

33. Hinderer, S., Layland, S.L., and Schenke-Layland, K. ECM and ECM-like materials Biomaterials for applications in regenerative medicine and cancer therapy. Adv Drug Deliv Rev 97, 260, 2016.

34. Syedain, Z.H., Meier, L.A., Bjork, J.W., Lee, A., and Tranquillo, R.T. Implantable arterial grafts from human fibroblasts and fibrin using a multi-graft pulsed flow-stretch bioreactor with noninvasive strength monitoring. Biomaterials 32, 714, 2011.

35. Li, X., Xu, J., Nicolescu, C.T., Marinelli, J.T., and Tien, J. Generation, Endothelialization, and Microsurgical Suture Anastomosis of Strong 1-mm-Diameter Collagen Tubes. Tissue Eng Part A 23, 335, 2017.

36. Gui, L., Boyle, M.J., Kamin, Y.M., et al. Construction of tissue-engineered smalldiameter vascular grafts in fibrin scaffolds in 30 days. Tissue Eng Part A 20, 1499, 2014.

37. Gilpin, A., and Yang, Y. Decellularization Strategies for Regenerative Medicine: From Processing Techniques to Applications. Biomed Res Int 2017, 9831534, 2017.

38. Lin, C.H., Hsia, K., Ma, H., Lee, H., and Lu, J.H. In Vivo Performance of Decellularized Vascular Grafts: A Review Article. Int J Mol Sci 19, 2018. 
39. Murphy, S.V., and Atala, A. 3D bioprinting of tissues and organs. Nat Biotechnol 32, 773, 2014.

40. Zhu, W., Qu, X., Zhu, J., et al. Direct 3D bioprinting of prevascularized tissue constructs with complex microarchitecture. Biomaterials 124, 106, 2017.

41. Visser, C.W., Kamperman, T., Karbaat, L.P., Lohse, D., and Karperien, M. In-air microfluidics enables rapid fabrication of emulsions, suspensions, and 3D modular (bio) materials. Science advances 4, eaao1175, 2018.

42. Grassl, E.D., Oegema, T.R., and Tranquillo, R.T. Fibrin as an alternative biopolymer to type-I collagen for the fabrication of a media equivalent. J Biomed Mater Res 60, 607, 2002.

43. Freeman, S., Ramos, R., Alexis Chando, P., et al. A bioink blend for rotary 3D bioprinting tissue engineered small-diameter vascular constructs. Acta Biomater 95, $152,2019$.

44. Rhee, S., Puetzer, J.L., Mason, B.N., Reinhart-King, C.A., and Bonassar, L.J. 3D Bioprinting of Spatially Heterogeneous Collagen Constructs for Cartilage Tissue Engineering. Acs Biomaterials Science \& Engineering 2, 1800, 2016.

45. Murphy, S.V., Skardal, A., and Atala, A. Evaluation of hydrogels for bio-printing applications. J Biomed Mater Res A 101, 272, 2013.

46. Diamantides, N., Wang, L., Pruiksma, T., et al. Correlating rheological properties and printability of collagen bioinks: the effects of riboflavin photocrosslinking and $\mathrm{pH}$. Biofabrication 9, 034102, 2017.

47. Tirella, A., Liberto, T., and Ahluwalia, A. Riboflavin and collagen: New crosslinking methods to tailor the stiffness of hydrogels. Materials Letters 74, 58, 2012.

48. Sun, J., and Tan, H. Alginate-Based Biomaterials for Regenerative Medicine Applications. Materials (Basel) 6, 1285, 2013.

49. Gao, G., Kim, H., Kim, B.S., et al. Tissue-engineering of vascular grafts containing endothelium and smooth-muscle using triple-coaxial cell printing. Applied Physics Reviews 6, 041402, 2019.

50. Gao, G., Lee, J.H., Jang, J., et al. Tissue Engineered Bio-Blood-Vessels Constructed Using a Tissue-Specific Bioink and 3D Coaxial Cell Printing Technique: A Novel Therapy for Ischemic Disease. Advanced Functional Materials 27, 1700798, 2017. 
51. Norotte, C., Marga, F.S., Niklason, L.E., and Forgacs, G. Scaffold-free vascular tissue engineering using bioprinting. Biomaterials 30, 5910, 2009.

52. Itoh, M., Nakayama, K., Noguchi, R., et al. Scaffold-Free Tubular Tissues Created by a Bio-3D Printer Undergo Remodeling and Endothelialization when Implanted in Rat Aortae. PLoS One 10, e0136681, 2015.

53. Badylak, S.F., and Gilbert, T.W. Immune response to biologic scaffold materials. Semin Immunol 20, 109, 2008.

54. Lu, H., Hoshiba, T., Kawazoe, N., and Chen, G. Autologous extracellular matrix scaffolds for tissue engineering. Biomaterials 32, 2489, 2011.

55. Crupi, A., Costa, A., Tarnok, A., Melzer, S., and Teodori, L. Inflammation in tissue engineering: The Janus between engraftment and rejection. Eur J Immunol 45, 3222, 2015.

56. Edri, R., Gal, I., Noor, N., et al. Personalized Hydrogels for Engineering Diverse Fully Autologous Tissue Implants. Adv Mater 31, e1803895, 2019.

57. Zhu, M., Li, W., Dong, X., et al. In vivo engineered extracellular matrix scaffolds with instructive niches for oriented tissue regeneration. Nat Commun 10, 4620, 2019.

58. Li, W., Midgley, A.C., Bai, Y., et al. Subcutaneously engineered autologous extracellular matrix scaffolds with aligned microchannels for enhanced tendon regeneration: Aligned microchannel scaffolds for tendon repair. Biomaterials 224, 119488, 2019.

59. Dietrich, M., Heselhaus, J., Wozniak, J., et al. Fibrin-based tissue engineering: comparison of different methods of autologous fibrinogen isolation. Tissue Eng Part C Methods 19, 216, 2013.

60. Konig, G., McAllister, T.N., Dusserre, N., et al. Mechanical properties of completely autologous human tissue engineered blood vessels compared to human saphenous vein and mammary artery. Biomaterials 30, 1542, 2009.

61. Grassl, E.D., Oegema, T.R., and Tranquillo, R.T. A fibrin-based arterial media equivalent. J Biomed Mater Res A 66, 550, 2003.

62. Aper, T., Wilhelmi, M., Gebhardt, C., et al. Novel method for the generation of tissueengineered vascular grafts based on a highly compacted fibrin matrix. Acta Biomater 29, 21, 2016. 
63. Noor, N., Shapira, A., Edri, R., Gal, I., Wertheim, L., and Dvir, T. 3D Printing of Personalized Thick and Perfusable Cardiac Patches and Hearts. Adv Sci (Weinh) 6, 1900344, 2019.

64. Badylak, S.F., and Gilbert, T.W. Immune response to biologic scaffold materials. Semin Immunol 20, 109, 2008.

65. Sadtler, K., Wolf, M.T., Ganguly, S., et al. Divergent immune responses to synthetic and biological scaffolds. Biomaterials 192, 405, 2019.

66. Peck, M., Dusserre, N., McAllister, T.N., and L'Heureux, N. Tissue engineering by selfassembly. Materials Today 14, 218, 2011.

67. L'Heureux, N., Paquet, S., Labbe, R., Germain, L., and Auger, F.A. A completely biological tissue-engineered human blood vessel. FASEB J 12, 47, 1998.

68. Peck, M., Gebhart, D., Dusserre, N., McAllister, T.N., and L'Heureux, N. The evolution of vascular tissue engineering and current state of the art. Cells Tissues Organs 195, 144, 2012.

69. L'Heureux, N., Stoclet, J.C., Auger, F.A., Lagaud, G.J., Germain, L., and Andriantsitohaina, R. A human tissue-engineered vascular media: a new model for pharmacological studies of contractile responses. FASEB J 15, 515, 2001.

70. McKee, J.A., Banik, S.S., Boyer, M.J., et al. Human arteries engineered in vitro. EMBO Rep 4, 633, 2003.

71. L'Heureux, N., Dusserre, N., Konig, G., et al. Human tissue-engineered blood vessels for adult arterial revascularization. Nat Med 12, 361, 2006.

72. L'Heureux, N., McAllister, T.N., and de la Fuente, L.M. Tissue-engineered blood vessel for adult arterial revascularization. N Engl J Med 357, 1451, 2007.

73. McAllister, T.N., Maruszewski, M., Garrido, S.A., et al. Effectiveness of haemodialysis access with an autologous tissue-engineered vascular graft: a multicentre cohort study. Lancet 373, 1440, 2009.

74. Wystrychowski, W., McAllister, T.N., Zagalski, K., Dusserre, N., Cierpka, L., and L'Heureux, N. First human use of an allogeneic tissue-engineered vascular graft for hemodialysis access. J Vasc Surg 60, 1353, 2014. 
75. von Bornstadt, D., Wang, H., Paulsen, M.J., et al. Rapid Self-Assembly of Bioengineered Cardiovascular Bypass Grafts From Scaffold-Stabilized, Tubular Bilevel Cell Sheets. Circulation 138, 2130, 2018.

76. Roostalu, U., Aldeiri, B., Albertini, A., et al. Distinct Cellular Mechanisms Underlie Smooth Muscle Turnover in Vascular Development and Repair. Circ Res 122, 267, 2018.

77. Kramann, R., Goettsch, C., Wongboonsin, J., et al. Adventitial MSC-like Cells Are Progenitors of Vascular Smooth Muscle Cells and Drive Vascular Calcification in Chronic Kidney Disease. Cell Stem Cell 19, 628, 2016.

78. Maier, J.A., Voulalas, P., Roeder, D., and Maciag, T. Extension of the life-span of human endothelial cells by an interleukin-1 alpha antisense oligomer. Science 249, 1570, 1990.

79. Lin, H., Du, Q., Li, Q., et al. Differentiating human pluripotent stem cells into vascular smooth muscle cells in three dimensional thermoreversible hydrogels. Biomater Sci 7, 347, 2018.

80. Bezenah, J.R., Kong, Y.P., and Putnam, A.J. Evaluating the potential of endothelial cells derived from human induced pluripotent stem cells to form microvascular networks in 3D cultures. Sci Rep 8, 2671, 2018.

81. Klein, D. iPSCs-based generation of vascular cells: reprogramming approaches and applications. Cell Mol Life Sci 75, 1411, 2018.

82. Wang, L., Hu, J., Sorek, C.E., Chen, E.Y., Ma, P.X., and Yang, B. Fabrication of tissueengineered vascular grafts with stem cells and stem cell-derived vascular cells. Expert Opin Biol Ther 16, 317, 2016.

83. Generali, M., Casanova, E.A., Kehl, D., et al. Autologous endothelialized small-caliber vascular grafts engineered from blood-derived induced pluripotent stem cells. Acta Biomater 97, 333, 2019.

84. Gui, L., Dash, B.C., Luo, J., et al. Implantable tissue-engineered blood vessels from human induced pluripotent stem cells. Biomaterials 102, 120, 2016.

85. Luo, J., Qin, L., Zhao, L., et al. Tissue-Engineered Vascular Grafts with Advanced Mechanical Strength from Human iPSCs. Cell Stem Cell 26, 251, 2020. 
86. Fathi-Achachelouei, M., Knopf-Marques, H., Ribeiro da Silva, C.E., et al. Use of Nanoparticles in Tissue Engineering and Regenerative Medicine. Front Bioeng Biotechnol 7, 113, 2019.

87. Hasan, A., Morshed, M., Memic, A., Hassan, S., Webster, T.J., and Marei, H.E. Nanoparticles in tissue engineering: applications, challenges and prospects. Int J Nanomedicine 13, 5637, 2018.

88. Mironov, V., Kasyanov, V., and Markwald, R.R. Nanotechnology in vascular tissue engineering: from nanoscaffolding towards rapid vessel biofabrication. Trends Biotechnol 26, 338, 2008.

89. Wolf, F., Paefgen, V., Winz, O., et al. MR and PET-CT monitoring of tissue-engineered vascular grafts in the ovine carotid artery. Biomaterials 216, 119228, 2019.

90. Chen, Y.W., Hsieh, S.C., Yang, Y.C., et al. Functional engineered mesenchymal stem cells with fibronectin-gold composite coated catheters for vascular tissue regeneration. Nanomedicine 14, 699, 2018.

91. Madhavan, R.V., Rosemary, M.J., Nandkumar, M.A., Krishnan, K.V., and Krishnan, L.K. Silver nanoparticle impregnated poly (varepsilon-caprolactone) scaffolds: optimization of antimicrobial and noncytotoxic concentrations. Tissue Eng Part A 17, 439, 2011.

92. Ito, A., Ino, K., Hayashida, M., et al. Novel methodology for fabrication of tissueengineered tubular constructs using magnetite nanoparticles and magnetic force. Tissue Eng 11, 1553, 2005.

93. Shimizu, K., Ito, A., Arinobe, M., et al. Effective cell-seeding technique using magnetite nanoparticles and magnetic force onto decellularized blood vessels for vascular tissue engineering. J Biosci Bioeng 103, 472, 2007.

94. Harrington, J.K., Chahboune, H., Criscione, J.M., et al. Determining the fate of seeded cells in venous tissue-engineered vascular grafts using serial MRI. FASEB J 25, 4150, 2011.

95. Nelson, G.N., Roh, J.D., Mirensky, T.L., et al. Initial evaluation of the use of USPIO cell labeling and noninvasive MR monitoring of human tissue-engineered vascular grafts in vivo. FASEB J 22, 3888, 2008. 
96. Edmundson, M., Thanh, N.T., and Song, B. Nanoparticles based stem cell tracking in regenerative medicine. Theranostics 3, 573, 2013.

97. Mertens, M.E., Koch, S., Schuster, P., et al. USPIO-labeled textile materials for noninvasive MR imaging of tissue-engineered vascular grafts. Biomaterials 39, 155, 2015.

98. Briley-Saebo, K.C., Johansson, L.O., Hustvedt, S.O., et al. Clearance of iron oxide particles in rat liver: effect of hydrated particle size and coating material on liver metabolism. Invest Radiol 41, 560, 2006.

99. Plan Sangnier, A., Van de Walle, A.B., Curcio, A., et al. Impact of magnetic nanoparticle surface coating on their long-term intracellular biodegradation in stem cells. Nanoscale 11, 16488, 2019.

100. Bergmeister, H., and Podesser, B.K. Preclinical In-Vivo Assessment of Tissue Engineered Vascular Grafts and Selection of Appropriate Animal Models. 1, 2020.

101. Bosma, M.J., and Carroll, A.M. The SCID mouse mutant: definition, characterization, and potential uses. Annu Rev Immunol 9, 323, 1991.

102. Lopez-Soler, R.I., Brennan, M.P., Goyal, A., et al. Development of a mouse model for evaluation of small diameter vascular grafts. J Surg Res 139, 1, 2007.

103. Chue, W.L., Campbell, G.R., Caplice, N., et al. Dog peritoneal and pleural cavities as bioreactors to grow autologous vascular grafts. J Vasc Surg 39, 859, 2004.

104. Cho, S.W., Jeon, O., Lim, J.E., et al. Preliminary experience with tissue engineering of a venous vascular patch by using bone marrow-derived cells and a hybrid biodegradable polymer scaffold. J Vasc Surg 44, 1329, 2006.

105. Swartz, D.D., and Andreadis, S.T. Animal models for vascular tissue-engineering. Curr Opin Biotechnol 24, 916, 2013.

106. Anderson, D.E.J., Pohan, G., Raman, J., Konecny, F., Yim, E.K.F., and Hinds, M.T. Improving Surgical Methods for Studying Vascular Grafts in Animal Models. Tissue Eng Part C Methods 24, 457, 2018.

107. Upputuri, P.K., Sivasubramanian, K., Mark, C.S., and Pramanik, M. Recent developments in vascular imaging techniques in tissue engineering and regenerative medicine. Biomed Res Int 2015, 783983, 2015. 

fibronectin coated PTFE grafts with cryopreserved saphenous vein endothelial cells. Thorac Cardiovasc Surg 35 Spec No 2, 143, 1987.

109. Zilla, P., Fasol, R., Preiss, P., et al. Use of fibrin glue as a substrate for in vitro endothelialization of PTFE vascular grafts. Surgery 105, 515, 1989.

110. Zilla, P., Fasol, R., Deutsch, M., et al. Endothelial cell seeding of polytetrafluoroethylene vascular grafts in humans: a preliminary report. J Vasc Surg 6, 535, 1987.

111. Müller-Glauser, W., Zilla, P., Lachat, M., et al. Immediate shear stress resistance of endothelial cell monolayers seeded in vitro on fibrin glue-coated ePTFE prostheses. Eur J Vasc Surg 7, 324, 1993.

112. Zilla, P., Deutsch, M., Meinhart, J., et al. Clinical in vitro endothelialization of femoropopliteal bypass grafts: an actuarial follow-up over three years. J Vasc Surg 19, 540, 1994.

113. Shinoka, T., Shum-Tim, D., Ma, P.X., et al. Creation Of Viable Pulmonary Artery Autografts Through Tissue Engineering. The Journal of Thoracic and Cardiovascular Surgery 115, 536, 1998.

114. Shin'oka, T., Imai, Y., and Ikada, Y. Transplantation of a tissue-engineered pulmonary artery. N Engl J Med 344, 532, 2001.

115. Matsumura, G., Miyagawa-Tomita, S., Shin'oka, T., Ikada, Y., and Kurosawa, H. First evidence that bone marrow cells contribute to the construction of tissue-engineered vascular autografts in vivo. Circulation 108, 1729, 2003.

116. Shin'oka, T., Matsumura, G., Hibino, N., et al. Midterm clinical result of tissueengineered vascular autografts seeded with autologous bone marrow cells. J Thorac Cardiovasc Surg 129, 1330, 2005.

117. Sung, Y.K., and Kim, S.W. Recent advances in the development of gene delivery systems. Biomater Res 23, 8, 2019.

118. Zhang, J., Qi, H., Wang, H., et al. Engineering of vascular grafts with genetically modified bone marrow mesenchymal stem cells on poly (propylene carbonate) graft. Artif Organs 30, 898, 2006. 
119. Stegemann, J.P., Dey, N.B., Lincoln, T.M., and Nerem, R.M. Genetic modification of smooth muscle cells to control phenotype and function in vascular tissue engineering. Tissue Eng 10, 189, 2004.

120. Anguela, X.M., and High, K.A. Entering the Modern Era of Gene Therapy. Annu Rev Med 70, 273, 2019.

121. Schott, J.W., Morgan, M., Galla, M., and Schambach, A. Viral and Synthetic RNA Vector Technologies and Applications. Mol Ther 24, 1513, 2016.

122. Warren, L., Manos, P.D., Ahfeldt, T., et al. Highly efficient reprogramming to pluripotency and directed differentiation of human cells with synthetic modified mRNA. Cell Stem Cell 7, 618, 2010.

123. Badieyan, Z.S., and Evans, T. Concise Review: Application of Chemically Modified mRNA in Cell Fate Conversion and Tissue Engineering. Stem Cells Transl Med 8, 833, 2019.

124. Patel, S., Athirasala, A., Menezes, P.P., et al. Messenger RNA Delivery for Tissue Engineering and Regenerative Medicine Applications. Tissue Eng Part A 25, 91, 2019.

125. Mandal, P.K., and Rossi, D.J. Reprogramming human fibroblasts to pluripotency using modified mRNA. Nat Protoc 8, 568, 2013.

126. Van Pham, P., Vu, N.B., Dao, T.T., Le, H.T., Phi, L.T., and Phan, N.K. Production of endothelial progenitor cells from skin fibroblasts by direct reprogramming for clinical usages. In Vitro Cell Dev Biol Anim 53, 207, 2017.

127. Lui, K.O., Zangi, L., Silva, E.A., et al. Driving vascular endothelial cell fate of human multipotent Is|1+ heart progenitors with VEGF modified mRNA. Cell Res 23, 1172, 2013.

128. Suknuntha, K., Tao, L., Brok-Volchanskaya, V., D'Souza, S.S., Kumar, A., and Slukvin, I. Optimization of Synthetic mRNA for Highly Efficient Translation and its Application in the Generation of Endothelial and Hematopoietic Cells from Human and Primate Pluripotent Stem Cells. Stem Cell Rev Rep 14, 525, 2018.

129. Lino, C.A., Harper, J.C., Carney, J.P., and Timlin, J.A. Delivering CRISPR: a review of the challenges and approaches. Drug Deliv 25, 1234, 2018.

130. Pickar-Oliver, A., and Gersbach, C.A. The next generation of CRISPR-Cas technologies and applications. Nat Rev Mol Cell Biol 20, 490, 2019. 
131. San Filippo, J., Sung, P., and Klein, H. Mechanism of eukaryotic homologous recombination. Annu Rev Biochem 77, 229, 2008.

132. Lieber, M.R. The mechanism of double-strand DNA break repair by the nonhomologous DNA end-joining pathway. Annu Rev Biochem 79, 181, 2010.

133. Zou, J., Maeder, M.L., Mali, P., et al. Gene targeting of a disease-related gene in human induced pluripotent stem and embryonic stem cells. Cell Stem Cell 5, 97, 2009.

134. Soldner, F., Laganiere, J., Cheng, A.W., et al. Generation of isogenic pluripotent stem cells differing exclusively at two early onset Parkinson point mutations. Cell 146, 318, 2011.

135. He, X., Tan, C., Wang, F., et al. Knock-in of large reporter genes in human cells via CRISPR/Cas9-induced homology-dependent and independent DNA repair. Nucleic Acids Res 44, e85, 2016.

136. Li, X.L., Li, G.H., Fu, J., et al. Highly efficient genome editing via CRISPR-Cas9 in human pluripotent stem cells is achieved by transient $B C L-X L$ overexpression. Nucleic Acids Res 46, 10195, 2018.

137. Merola, J., Reschke, M., Pierce, R.W., et al. Progenitor-derived human endothelial cells evade alloimmunity by CRISPR/Cas9-mediated complete ablation of MHC expression. JCI Insight 4, 2019.

138. Jang, Y., Choi, J., Park, N., et al. Development of immunocompatible pluripotent stem cells via CRISPR-based human leukocyte antigen engineering. Exp Mol Med 51, 1, 2019.

139. Chang, C.Y., Ting, H.C., Su, H.L., and Jeng, J.R. Combining Induced Pluripotent Stem Cells and Genome Editing Technologies for Clinical Applications. Cell Transplant 27, 379, 2018.

140. Taylor, C.J., Peacock, S., Chaudhry, A.N., Bradley, J.A., and Bolton, E.M. Generating an iPSC bank for HLA-matched tissue transplantation based on known donor and recipient HLA types. Cell Stem Cell 11, 147, 2012.

141. Han, X., Wang, M., Duan, S., et al. Generation of hypoimmunogenic human pluripotent stem cells. Proc Natl Acad Sci U S A 116, 10441, 2019. 


\section{Figure legends}

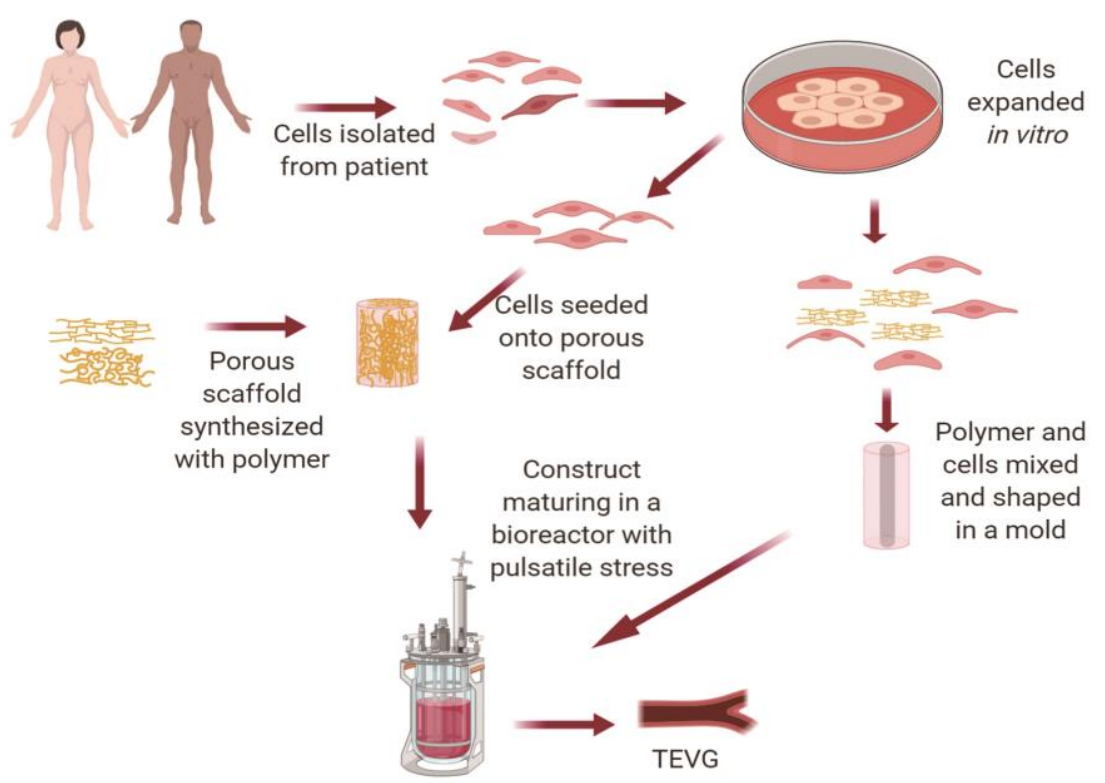

FIG. 1. Manufacturing scaffold-based TEVG. Tissues are harvested from patients and specific types of cells isolated and cultured in vitro. Cells are seeded onto a porous scaffold or mixed with polymers, such as synthetic polymer or natural polymer, to shape in a tubular mold. The TEVG is incubated in a bioreactor with mechanical stimulation. The figure was created with BioRender.com and modified by PhotoFiltre 7. 


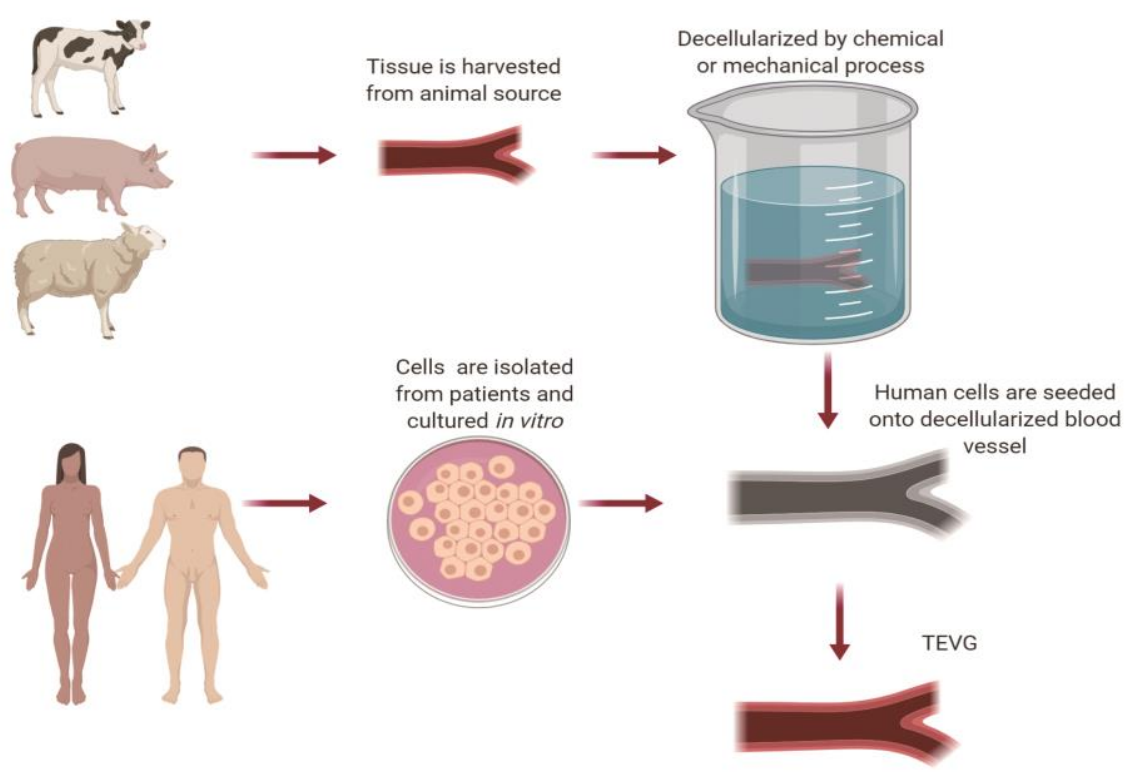

FIG. 2. TEVG is generated from decellularized matrices. Vascular tissues are harvested from animal (bovine, ovine, or porcine) sources. Vascular tissues are decellularized to remove genetic material or cells by chemical, enzymatic or physical methods or their combinations. Cells are harvested and isolated from patients and expanded in vitro. Cells are seeded onto decellularized construct and incubated for TEVG formation. The figure was created with BioRender.com and modified by PhotoFiltre 7. 


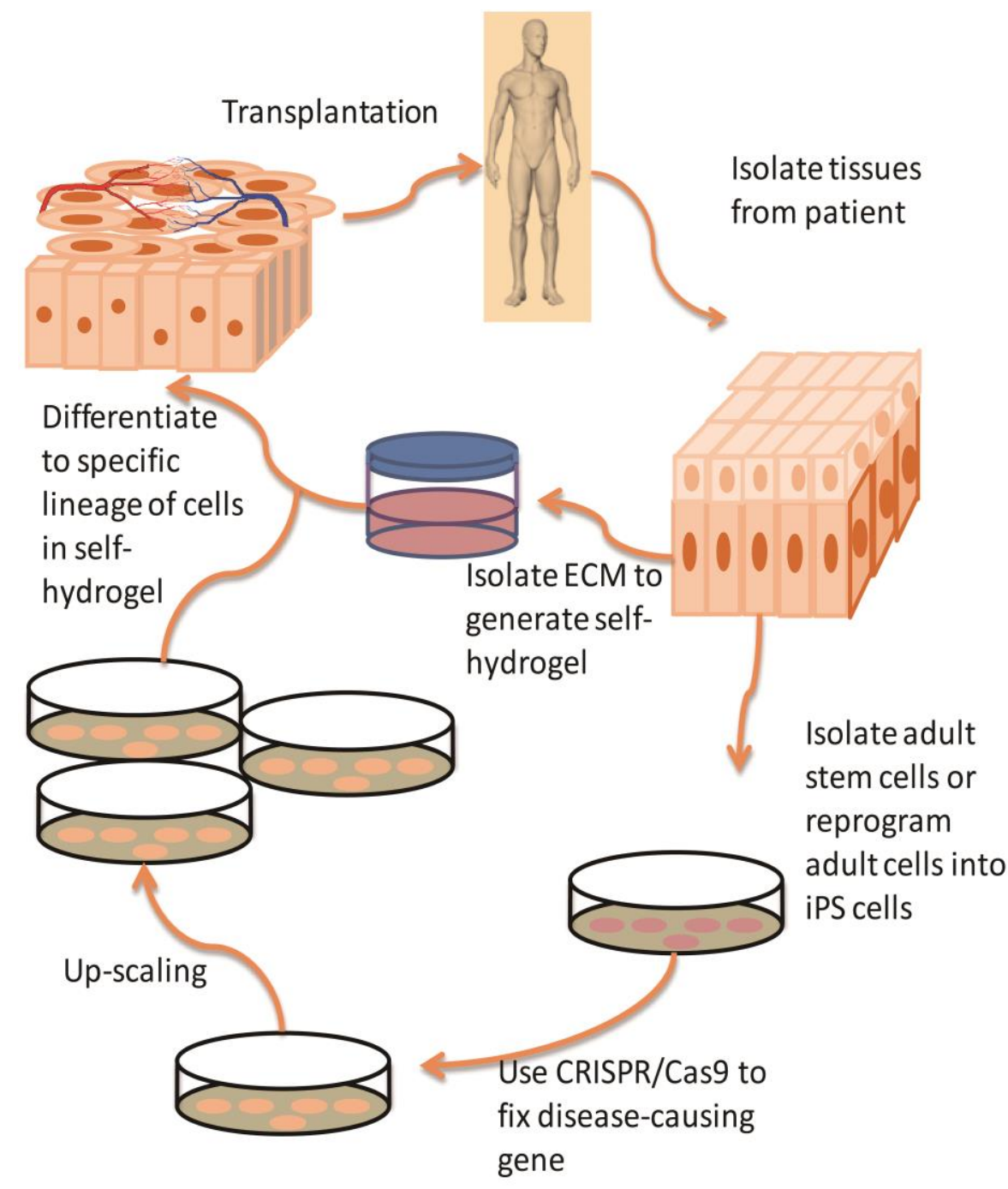

FIG. 3. Personalized vascular tissue. Tissues are harvested from a patient. Cells and extracellular matrix are isolated from the patient's tissues. The extracellular matrix is manipulated as the self-hydrogel. Adults stem cells are isolated or well-differentiated adult cells are reprogrammed into iPSCs. Disease-causing genes are modified with CRISPR/Cas9. The gene-fixed stem cells are expanded in vitro and differentiated in the self-hydrogel to produce autologous vascular tissue blocks. The personalized tissue blocks are transplanted back into the patient. 


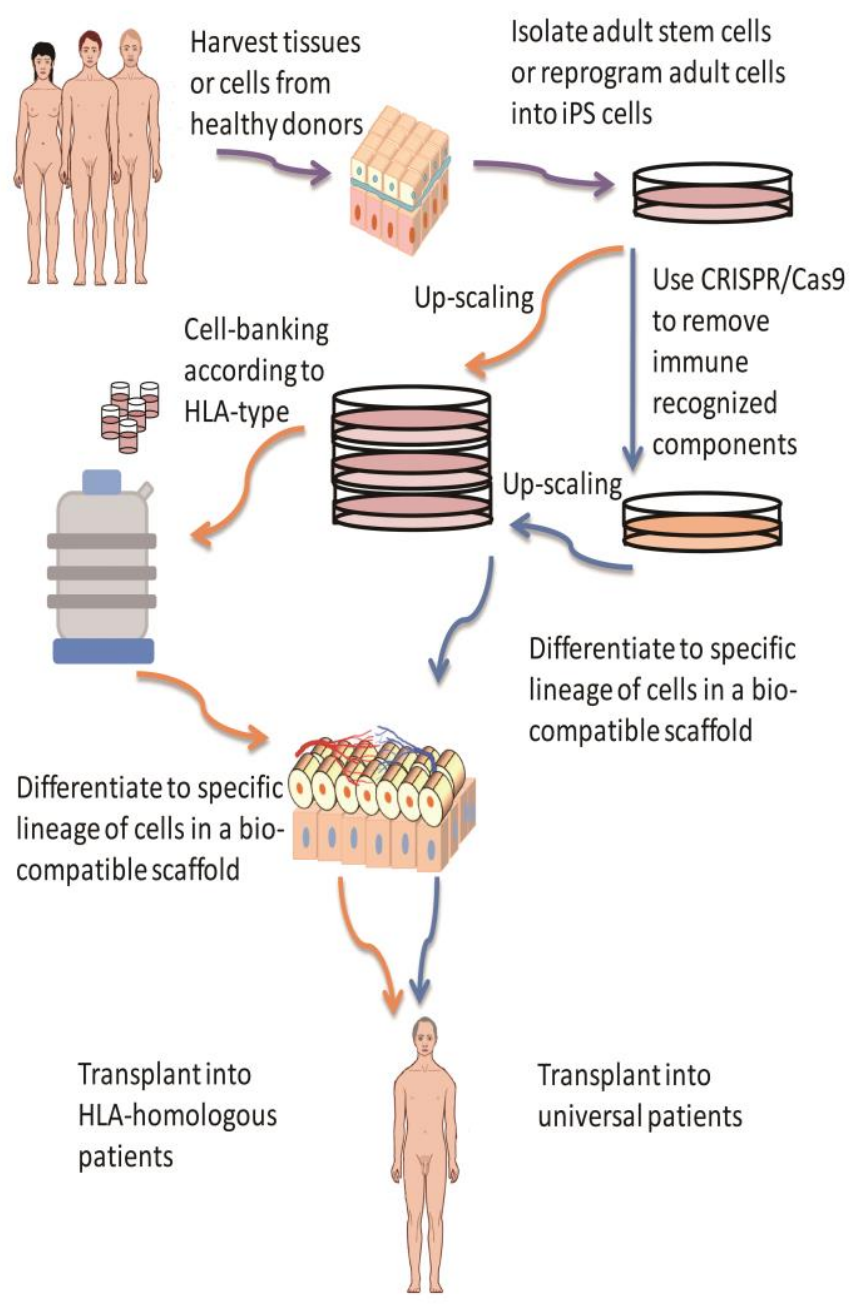

FIG. 4. The ideal off-the-shelf vascular tissue. Tissues are harvested from healthy donors. Adult stem cells are isolated from donor tissues and expanded in vitro. Well-differentiated adult cells are reprogrammed into iPSCs and propagated in vitro. (Orange arrows) Stem cells are banked according to their HLA-type. Stem cells are differentiated in biocompatible scaffold to generate vascular tissue in vitro. Tissue blocks are transplanted into HLAhomologous patients. (Blue arrows) Stem cells are manipulated with CRISPR/Cas9 to remove immune-recognized components and trigger expression of PD-L1, HLA-G, and CD47 to decrease the immune response. Hypoimmunogenic stem cells are differentiated in a biocompatible scaffold to generate vascular tissue in vitro. Hypoimmunogenic tissue blocks can be transplanted into universal patients. 
Table 1. The progress of cell-based tissue-engineered vascular grafts

\begin{tabular}{|c|c|c|c|c|c|}
\hline $\begin{array}{l}\text { Cell } \\
\text { sources }\end{array}$ & Graft & Animal model & Clinical study & $\begin{array}{l}\text { Patency } \\
\text { determination }\end{array}$ & $\begin{array}{l}\text { Referenc } \\
\text { es }\end{array}$ \\
\hline $\begin{array}{l}\text { Autologo } \\
\text { us human } \\
\text { saphenou } \\
\text { s vein ECs }\end{array}$ & $\begin{array}{l}\text { Fibronecti } \\
\text { n-coated } \\
\text { PTFE }\end{array}$ & $\begin{array}{l}\text { Canine } \\
\text { (Autologous } \\
\text { venous ECs) }\end{array}$ & $\begin{array}{l}\text { Patients who } \\
\text { had no } \\
\text { saphenous } \\
\text { vein available }\end{array}$ & $\begin{array}{l}\text { Doppler } \\
\text { ultrasound } \\
\text { Angiography }\end{array}$ & $14,108-112$ \\
\hline $\begin{array}{l}\text { Autologo } \\
\text { us } \\
\text { peripheral } \\
\text { vein } \\
\text { Autologo } \\
\text { us bone } \\
\text { marrow } \\
\text { cells }\end{array}$ & $P C L+P L A$ & $\begin{array}{l}\text { Ovine } \\
\text { (Autologous veins } \\
\text { or artery) } \\
\text { Canine } \\
\text { (Autologous bone } \\
\text { marrow cells) }\end{array}$ & $\begin{array}{l}\text { A girl with } \\
\text { occlusion of } \\
\text { pulmonary } \\
\text { artery } \\
\text { Patients for } \\
\text { extracardiac } \\
\text { total } \\
\text { cavopulmona } \\
\text { ry connection } \\
\text { or the repair } \\
\text { of congenital } \\
\text { heart defects }\end{array}$ & $\begin{array}{l}\text { Chest } \\
\text { radiography } \\
\text { Angiography } \\
\text { Doppler } \\
\text { echocardiograp } \\
\text { hy } \\
\text { Catheterization } \\
\text { Computed } \\
\text { tomographic } \\
\text { scan }\end{array}$ & $113-116$ \\
\hline $\begin{array}{l}\text { Human } \\
\text { SMCs and } \\
\text { fibroblast } \\
\text { s }\end{array}$ & $\begin{array}{l}\text { Self- } \\
\text { assembly }\end{array}$ & $\begin{array}{l}\text { Nude rats } \\
\text { (Human TEVGs) } \\
\text { Immunosuppress } \\
\text { ed cynomolgus } \\
\text { macaques } \\
\text { (Human TEVGs) }\end{array}$ & $\begin{array}{l}\text { Patients } \\
\text { diagnosed } \\
\text { with } \\
\text { arteriovenous } \\
\text { shunt failure }\end{array}$ & $\begin{array}{l}\text { Computed } \\
\text { tomographic } \\
\text { angiography } \\
\text { Doppler } \\
\text { ultrasonograph } \\
\text { y }\end{array}$ & $71,72,74$ \\
\hline
\end{tabular}

